\title{
Pengembangan Pemasaran Online Usaha Kerajinan Enceng Gondok dan Pandan di Desa Lopait Kecamatan Tuntang Kabupaten Semarang
}

\author{
Atmoko Nugroho \\ Fakultas Teknologi Informasi dan \\ Komunikasi \\ Universitas Semarang \\ Semarang \\ atmoko@usm.ac.id
}

\author{
April Firman Daru \\ Fakultas Teknologi Informasi dan \\ Komunikasi \\ Universitas Semarang \\ Semarang \\ Firman@usm.ac.id
}

\author{
Whisnumurti Adhiwibowo \\ Fakultas Teknologi Informasi dan \\ Komunikasi \\ Universitas Semarang \\ Semarang \\ whisnu@usm.ac.id
}

\begin{abstract}
Abstrak - Pemasaran yang dilakukan oleh pengrajin handycraft di Desa Lopait Kecamatan Tuntang Kabupaten Semarang, menggunakan pemodelan pemasaran tradisional, yang hanya bergantung kepada tempat pengrajin memamerkan produk mereka. Keterbatasan pemasaran yang bergantung hanya kepada tempat produksi atau lokasi sekitar tempat produksi menyebabkan rendahnya tingkat penjualan.

Perkembangan Teknologi Informasi yang semakin pesat membuat pola pemasaran mengalami perubahan, pemanfaatan internet menjadi salah satu alternatif yang banyak dipakai perusahaan untuk memasarkan produknya. Dengan adanya situs online maka kesempatan pengembangan pemasarana akan semakin besar karena jumlah pengunjung tidak hanya berasal dari kota sekitar atau daerah sekitar akan tetapi seluruh pengguna internet. Informasi produk baru hingga perubahan harga dapat dilihat secara langsung dari situs pengrajin. Dengan adanya situs online diharapkan masyarakat dunia akan mengetahui adanya produk-produk dari desa Lopit. Sebagai alternatif memecahkan masalah akan dikembangkan model pemasaran secara online, yang tidak mengenal batasan dan waktu dalam pemasarannya. Model pengembangan sistem yang dipakai dalam membuat web ini adalah System Develop Life Cycle (SDLC).
\end{abstract}

Kata Kunci - Pemasaran online, handycraft, SDLC

\section{PENDAHULUAN}

Pemasaran online atau perdagangan elektronik (atau $e$ commerce) adalah penyebaran, pembelian, penjualan, pemasaran barang dan jasa melalui sistem elektronik seperti internet atau televisi, www, atau jaringan komputer lainnya [1]. Dengan kondisi saat ini, batasan atau pemisahan antara berbagai produk seperti komputer dan televisi telah mengalami mengabur (konvergensi) [2], sehingga menyebabkan penggunaan e-commerce dari tahun ke tahun akan terus meningkat.

Pemasaran yang dilakukan oleh pengrajin handycraft di Desa Lopait Kecamatan Tuntang Kabupaten Semarang, menggunakan pemodelan pemasaran tradisional, yang hanya bergantung kepada tempat pengrajin memamerkan produk mereka. Pengembangan pemasaran terbatas kepada lokasi atau tempat pengrajin melakukan produksi dan penjualan. Keterbatasan tersebut yang menyebabkan perkembangan jumlah produksi mengalami pasang-surut dan dengan jumlah produksi yang tidak begitu banyak.

UKM pengrajin enceng gondok atau pandan di desa lopait terdapat lebih dari 20 pengrajin yang tersebar di kecamatan tuntang. Kebutuhan enceng gondok dan pandan bersumber dari olahan warga sekitar rawa pening dan dapat dipastikan bahwa jumlah yang dihasilkan melebihi jumlah kebutuhan untuk produksi pengrajin handycraft di Desa Lopait sehingga produksi enceng gondok tersebut dipasarkan hingga kota-kota lain. Dengan kondisi tersebut, tidak diimbangi dengan produksi handycraft oleh UKM sekitar.

Adapun permasalahan yang dihadapi oleh UKM adalah : produksi yang dilakukan, tidak melalui tahapan desain terlebih dahulu, akan tetapi melalui metode prototipe yang terkadang tidak melihat pangsa pasar atau melihat kebutuhan pasar, Lokasi penjualan bergantung kepada lokasi produksi sehingga kesempatan untuk memperoleh pangsa pasar yang lebih luas menjadi terhambat, untuk memperluas usahanya dan meningkatkan omset dibutuhkan promosi atau pameran yang membutuhkan biaya yang tidak sedikit, pemasaran dan pengembangan usaha yang dilakukan masih menggunakan metode konvensional, yang bergantung kepada lokasi. Keterbatasan pemasaran yang bergantung hanya kepada tempat produksi atau lokasi sekitar tempat produksi maka menyebabkan rendahnya tingkat penjualan yang berakibat kepada dampak penyerapan tenaga kerja, tingkat kesejahteraan masyarakat pengrajin handycraft dan ketidakpastian akan jumlah produksi. Sebagai solusi kami menawarkan model pemasaran secara online, yang tidak mengenal batasan dan waktu dalam pemasarannya 


\section{KAJIAN LITERATUR}

\section{A. E-commerce}

Electronic Commerce (E-Commerce) adalah proses pembelian dan penjualan produk, jasa dan informasi yang dilakukan secara elektronik dengan memanfaatkan jaringan computer. E-commerce juga mengandung pengertian sebagai penyebaran, pemasaran jasa, melalui system elektronik seperti internet atau jaringan computer lainnya. E-commerce dapat melibatkan transfer dana elektronik,system manajemen inventory otomatis dan system pengumpulan data otomatis.

Sementara itu Kalakota dan Whinston mendefinisikan ECommerce dari beberapa perspektif, yaitu:

1. Dari perspektif komunikasi, E-Commerce adalah pengiriman informasi, produk/jasa, atau pembayaran melalui jaringan telepon, atau jalur komunikasi lainnya;

2. Dari perspektif proses bisnis, E-Commerce adalah aplikasi teknologi menuju otomatisasi transaksi bisnis dan work flow;

3. Dari perspektif pelayanan, E-Commerce adalah alat yang digunakan untuk mengurangi biaya dalam pemesanan dan pengiriman barang; dan

4. Dari perspektif online, E-Commerce menyediakan kemampuan untuk menjual dan membeli produk serta informasi melalui internet dan jaringan jasa online lainnya.

menyatakan E-Commerce adalah penggunaan jaringan komputer untuk melakukan komunikasi bisnis dan transksaksi komersial. Kemudian di website E-Commerce Net, ECommerce didefinisikan sebagai kegiatan menjual barang dagangan dan/atau jasa melalui internet. Seluruh komponen yang terlibat dalam bisnis praktis diaplikasikan disini, seperti customer service, produk yang tersedia, cara pembayaran, jaminan atas produk yang dijual, cara promosi dan sebagainya.

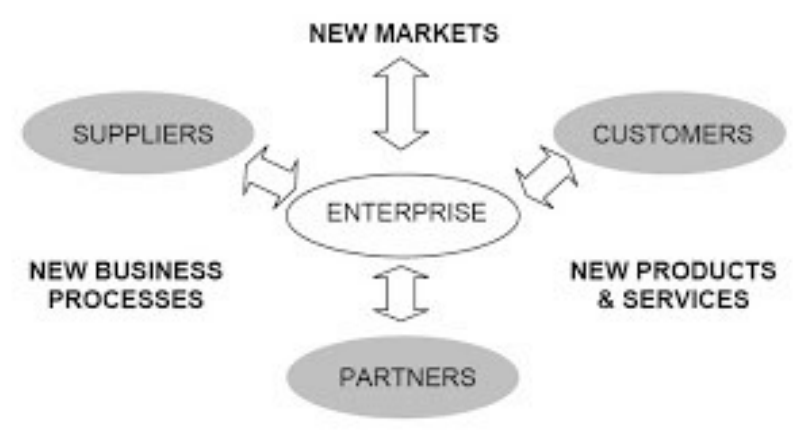

Gambar 1. Alur E-commerce

\section{$B$. Internet Marketing}

Internet marketing merupakan model pemasaran yang dilakukan dengan bantuan internet. Kegiatan pemasaran internet marketing sering juga disebut e-pemasaran atau elektronik pemasaran. Elektronik disini berarti kegiatan pemasaran dilakukan secara elektronik.

Pemasaran berbasis internet ini bisa dilakukan dengan berbagai macam cara, diantaranya : dengan membuat web commerce, beriklan lewat portal pemasaran atau juga bisa dilakukan lewat sosial media. Namun pencarian uang lewat internet tidak dapat dikatan sebagai internet marketing

\section{SEO (Search Engine Optimization)}

SEO dapat diartikan sebagai optimasi mesin pencari, sebuah web dapat memiliki nilai tambah bila terindeks pada mesin pencari, misalnya google. Apabila web atau situs berada pada posisi teratas ketika suatu kata kunci diketikkan pada mesin pencari, maka web tersebut akan mudah ditemukan. SEO (Search Engine Optimization/Optimasi Mesin Pencari) adalah serangkaian proses yang dilakukan secara sistematis yang bertujuan untuk meningkatkan volume/jumlah/kepadatan dan kualitas trafik/traffic kunjungan melalui mesin pencari menuju situs web tertentu dengan memanfaatkan mekanisme kerja ataua lgoritma mesin pencari tersebut.

Apabila user mencari situs dengan memanfaatkan mesin pencari disebut dengan "trafik alami" sedangkan saat ujser mengunjungi suatu situs karena informasi dari seseorang adalah kebalikan dari "trafik alami" hal itu tidak termasuk SEO walaupun nantinya ada pengaruhnya buat SEO itu sendiri

\section{UML(Unified Modeling Language)}

Proses perancangan aplikasi pemasaran on line ini menggunakan UML, dalam perancangannya melalui tahapan mulai dari Use case Diagram, Sequence Diagram, Aktivity Diagram.

Unified Modeling Language (UML) adalah himpunan struktur dan teknik untuk pemodelan desain program berorientasi objek (OOP) serta aplikasinya.[1] UML adalah metodologi untuk mengembangkan sistem OOP dan sekelompok perangkat tool untuk mendukung pengembangan sistem tersebut.[1] UML mulai diperkenalkan oleh Object Management Group, sebuah organisasi yang telah mengembangkan model, teknologi, dan standar OOP sejak tahun 1980-an.[1] Sekarang UML sudah mulai banyak digunakan oleh para praktisi OOP.[1] UML merupakan dasar bagi perangkat (tool) desain berorientasi objek dari IBM.[1]

UML adalah suatu bahasa yang digunakan untuk menentukan, memvisualisasikan, membangun, dan mendokumentasikan suatu sistem informasi.[5] UML dikembangkan sebagai suatu alat untuk analisis dan desain berorientasi objek oleh Grady Booch, Jim Rumbaugh, dan Ivar Jacobson.[5] Namun demikian UML dapat digunakan untuk memahami dan mendokumentasikan setiap sistem informasi.[5] Penggunaan UML dalam industri terus meningkat.[5] Ini merupakan standar terbuka yang menjadikannya sebagai bahasa pemodelan yang umum dalam industri peranti lunak dan pengembangan sistem.[5]Sampai era tahun 1990 puluhan metodologi pemodelan berorientasi objek telah bermunculan di dunia.[2] Diantaranya adalah: metodologi booch, metodologi coad, metodologi OOSE, metodologi OMT, metodologi shlaer-mellor, metodologi wirfs-brock, dsb.[2] Masa itu terkenal dengan masa perang metodologi (method war) dalam pendesainan berorientasi objek.[2] Masing-masing metodologi membawa notasi sendiri-sendiri, yang mengakibatkan timbul masalah baru 
apabila kita bekerjasama dengan kelompok/perusahaan lain yang menggunakan metodologi yang berlainan.[2]

Use case diagram digunakan untuk memodelkan bisnis proses berdasarkan perspektif pengguna sistem. [3]Use case diagram terdiri atas diagram untuk use case dan actor.[3] Actor merepresentasikan orang yang akan mengoperasikan atau orang yang berinteraksi dengan sistem aplikasi.[3]

Use case merepresentasikan operasi-operasi yang dilakukan oleh actor.[4] Use case digambarkan berbentuk elips dengan nama operasi dituliskan di dalamnya. Actor yang melakukan operasi dihubungkan dengan garis lurus ke use case.[3]

Diagram Class dan diagram Object merupakan suatu gambaran model statis.Namun ada juga yang bersifat dinamis, seperti Diagram Interaction.Diagram sequence merupakan salah satu diagram Interaction yangmenjelaskan bagaimana suatu operasi itu dilakukan; message (pesan) apa yang dikirimdan kapan pelaksanaannya. Diagram ini diatur berdasarkan waktu. Obyek-obyek yang berkaitan dengan proses berjalannya operasi diurutkan dari kiri ke kanan berdasarkan waktu terjadinya dalam pesan yang terurut.

\section{METODE PENELITIAN}

\section{A. Jenis Penelitian}

Penelitian yang dipakai untuk mengembangkan aplikasi penjualan online ini adalah penelitian rekayasa, adalah kegiatan merancang desain yang tidak rutin, yang didalamnya ada kontribusi baru, dalam bentuk proses maupun produk (Ali Amran, 1997)

\section{B. Prosedur Penelitian}

Penelitian ini dilakukan beberapa tahap sebagai berikut :

1. Persiapan pembuatan web-ecommerce

Langkah awal dalam pembuatan web-commerce adalah melakukan pencarian data, yaitu data primer dan data sekunder. Data primer didapatkan dari wawancara dengan subyek penelitian yaitu ibu Kadarini pemiliki Aryani art dan Bp. Koencoro Pemiliki Koen gallery. Untuk data sekunder didapat dari literar, baik dari buku maupun dari internet

2. Pembuatan web-commerce

Pembuatan aplikasi web-commerce dilakukan dengan menggunakan metode System Develop Life Cycle. Adapun tahapan tahapannya dari planning, analizing, implementation, testing and evaluation. Adapun tahapan nya sebagai berikut:

\subsection{Planning}

Mengenali masalah dalam pemasaran produk dari UKM, untuk selanjutnya masalah masalah tersebut diidentifikasi. Setelah masalah diidentifikasi, langkah selanjutnya adalah menetapkan tujuan, yaitu memecahkan masalah pemasaran yang kurang berkembang. Untuk itu perlu dilakukan pendataan ahmbatan-hambatan yang muncul untuk selanjutnya dicari jalan keluarnya.

\subsection{Sistem Analys}

Untuk dapat menganalisa sistem, langkah pertama yang harus dilakukan adalah menganalisa data yang diperoleh, baik data primer maupun sekunder. Setelah itu menentukan kebutuhan informasi baik dari user maupun administratior. Kedua hal diatas penting karena berkaitan dengan penentuan performance system yang akan dibuat

\subsection{Sistem Design}

Langkah penting selanjutnya adalah Sistem Design. Yang dilakukan pada tahap ini diantaranya adalah menyiapkan detail design, kemudian mengidentifikasi konfigurasi alternatif sistem, dilanjutkan dengan mengevaluas konfigurasi dari alteniatif sistem dan akhimya memilih konfigurasi yang terbaik.

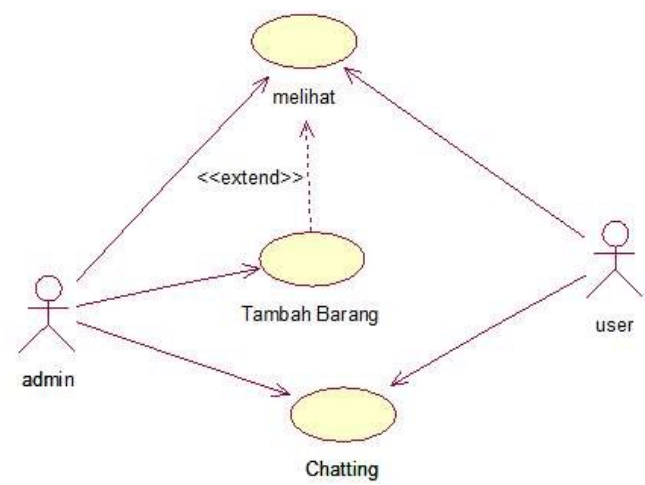

Gambar 2. Use Case Diagram

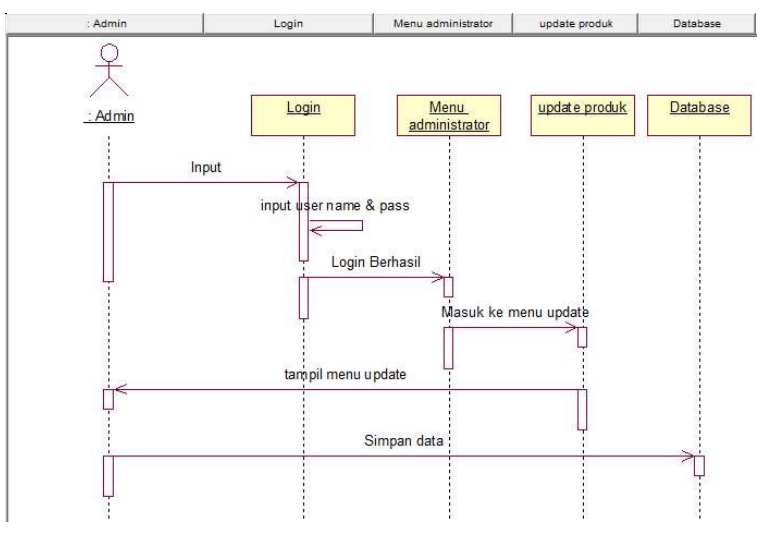

Gambar 3. Sequence diagram 


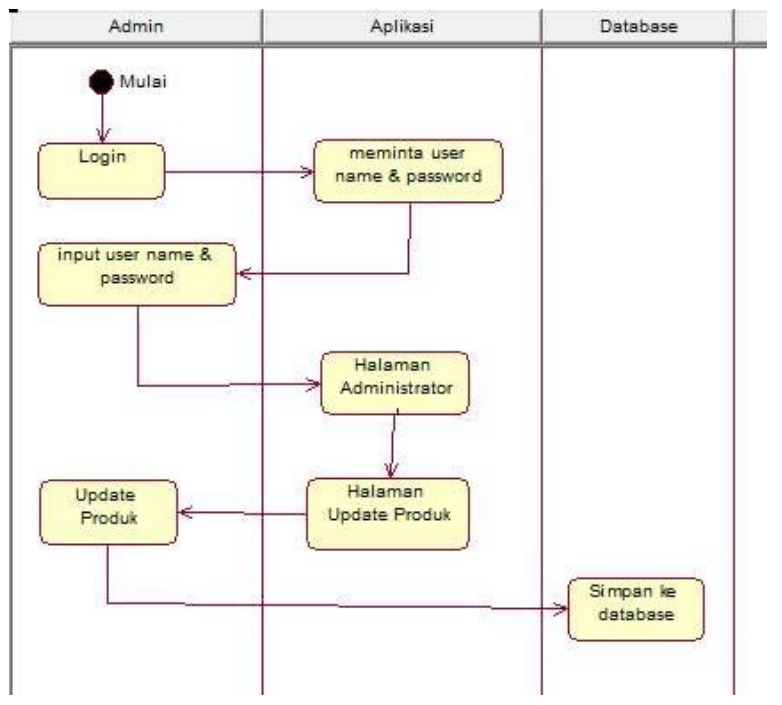

Gambar 4. Aktivitas Diagram

\subsection{Sistem Implementation}

Setelah tahap desain, langkah penting yang harus dilakukan adalah implementasi sistem. Pada tahap ini sistem yang telah dibuat diimplementasikan apakah sudah seduai dengan rencana yang ditetapkan. Kemampuan sistem harus dapat menjawab kebutuhan. Dalam hal ini aplikasi harus berbasis web dan on line, karena diharapkan dapat memberikan informasi produk UKM kepada para konsumen dengan area yang jauh lebih luas. Pengelolaan SEO (Search Engine Optimize) juga harus diperhatikan, karena SEO yang baik akan membuat aplikasi berbasis web dapat terindeks di google, sehingga akan mudah dalam pencariannya

\subsection{Sistem Operation and Maintenance}

Kegiatan pemeliharaan harus dilakukan nuntuk mengantisipasi kerusakan sistem. Dalam kasus ini, kerusakan sistem bisa saja terjadi dari pihak luar atau kompetitor. Penerapan sistem keamanan yang baik multak diperlukan. Hal ini sebagai pencegahan agar aplikasi tidak dapat diretas. Selain itu, aktifitas ini njuga dapat memberikan masukan mengenai kekurangan sistem, melalui informasi ini, aplkasi dapat terus ditingkatkan kemampuannya

2.6. Pengujian Sistem

Aplikasi yang telah dibuat harus melalui 2 tahap pengujian, yaitu uji Black Box dan uji White Box, melalui dua pengujian tersebut akan dapat ditemukan kekurangan sistem, baik melalui fungsionalitas sistem maupun struktur pemrogramannya.

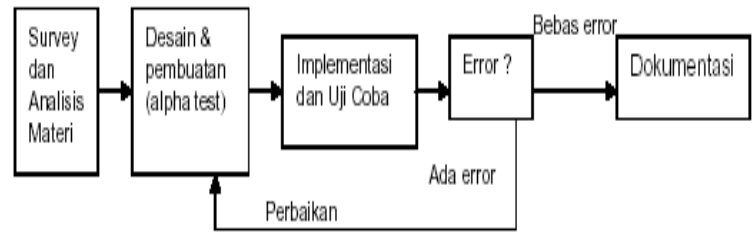

Gambar 5. Siklus Pengembangan Aplikasi WebCommerce

\subsection{Evaluasi}

Melalui tahap evaluasi akan diketahui kekurangan dan kelebihan sistem, agar dapat didata dan dilakukan follow up sehingga aplikasi dapat selalu disempurnakan yang pada akhirnya dapat mencapai tujuan yang diharapkan.

\section{HASIL DAN PEMBAHASAN}

Adapun hasil dari pengembangan aplikasi web-commerce yang telah dilakukan adalah sebagai berikut :

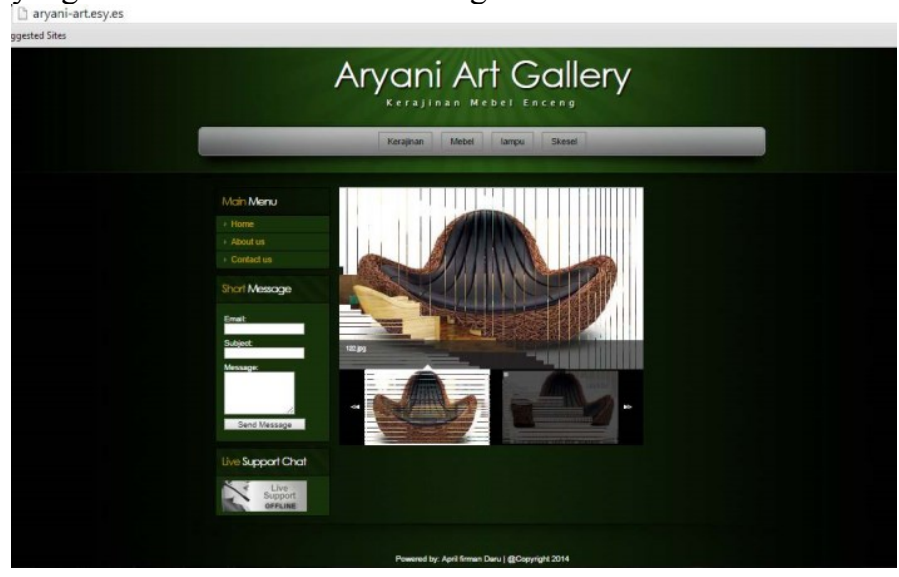

Gambar 6. Halaman depan aplikasi 


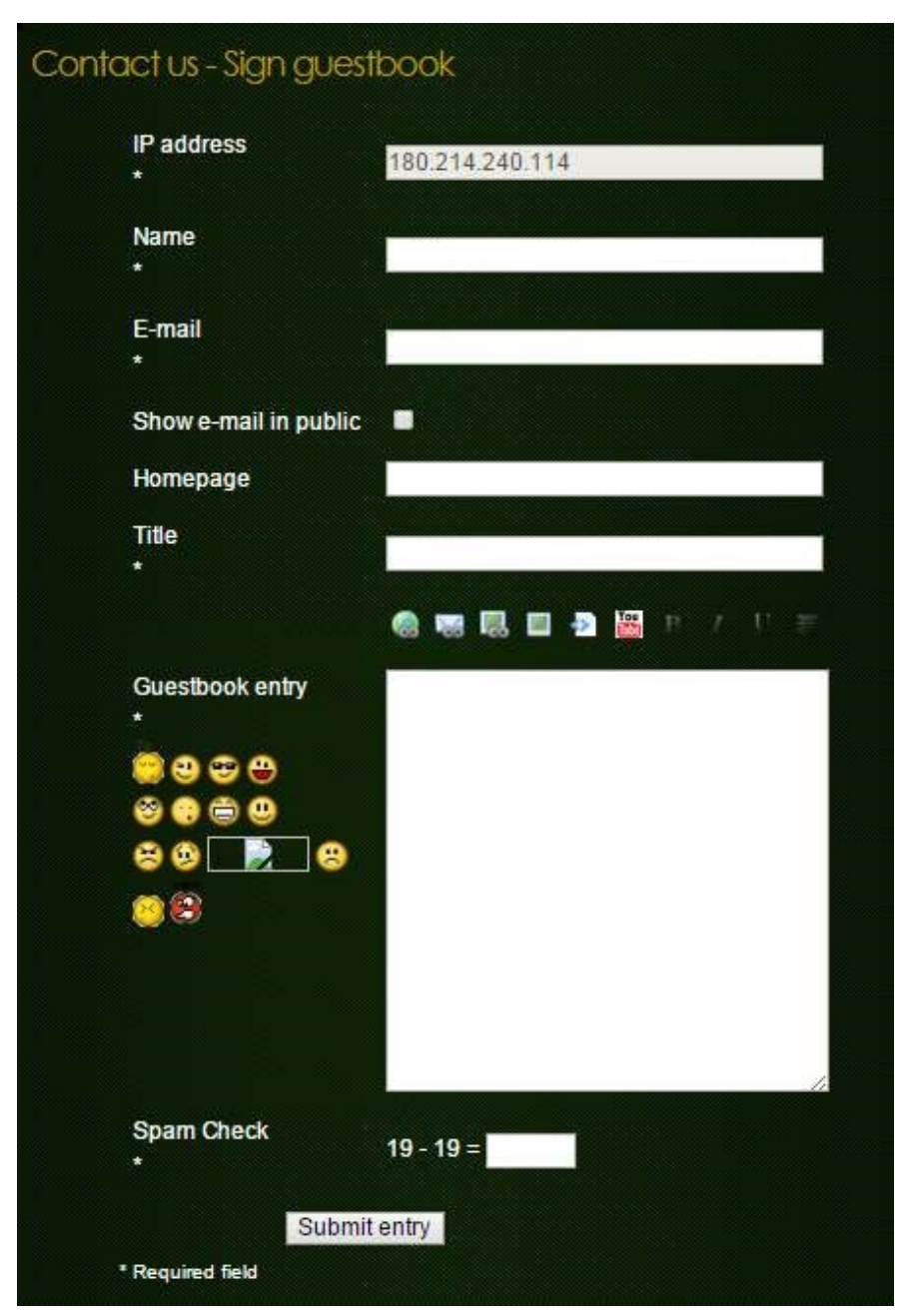

Gambar 7. Buku Tamu

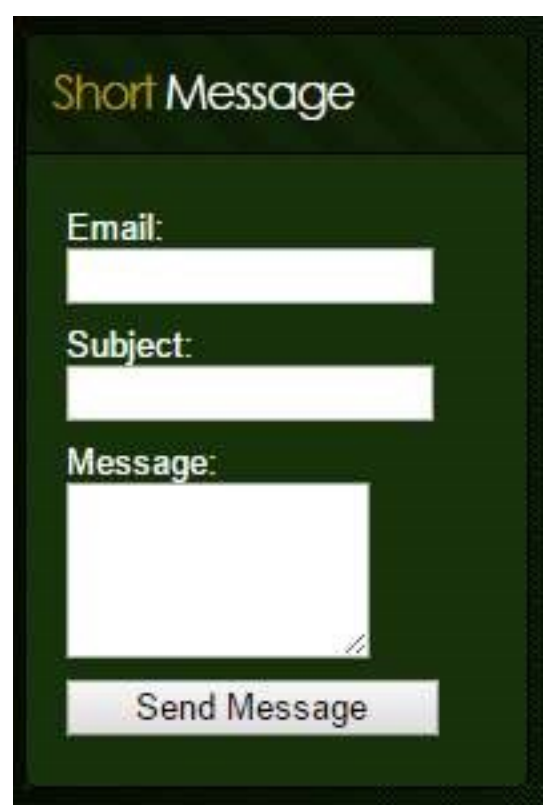

Gambar 8. Instant Message

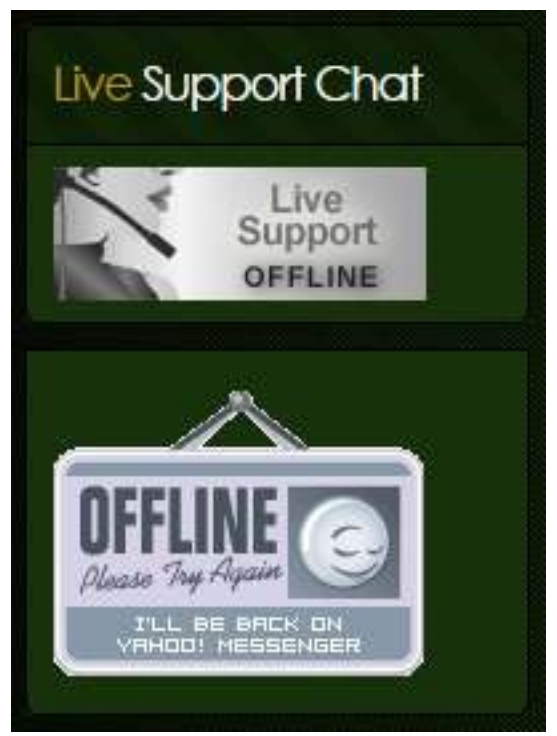

Gambar 9. Fasilitas Chatting

\section{KESIMPULAN}

Model pemasaran konvensional mensyaratkan banyak biaya dengan segala keterbatasannya. Dengan berkembangnya teknologi informasi dan murahnya akses internet membawa dampak semakin mudahnya mengembangkangkan pemasaran on line. Pemanfaatan internet untuk memasarkan suatu produk memiliki jangkauan lebih luas dibanding memasarkan secara konvensional. Konsumen dapat melihat dan mempelajari produk tanpa dibatasi ruang dan waktu, selama akses internet ada. Web commerce yang dibuat untuk aryani art dan koen gallery menjadi sarana pemasaran yang efektik untuk menjangkau konsumen yang leih luas diberbagai belahan dunia. Melalui cara ini, aryani art dan koen gallery memasuki pemasaran tanpa batas.

\section{REFERENSI}

[1] David M. Kroenke, Database Processing Jilid 1 edisi 9, halaman 60. Erlangga.1

[2] Dharwiyanti (2003), Pengantar Unified Modeling Language (UML), IlmuKomputer.Com.3

[3] FARID AZIS, M. Kom, Object Oriented Programming Php 5, halaman 118. Elex Media Komputindo.4

[4] Julius Hermawan, Analisis Desain \& Pemrograman Berorientasi Obyek dengan UML dan Visual Basic.NETby Danoe Mraz.5

[5] Rama, Jones, Sistem Informasi Akuntansi halaman 78 Salemba.2

[6] http://elearning.gunadarma.ac.id/docmodul/modul introd uction e-commerce/d.BAB $\% 20 I-P e n g e r t i a n \% 20 \mathrm{E}^{-}$ commerce.pdf

[7] http://jurnal-sdm.blogspot.com/2009/08/e-commersedefinisi-jenis-tujuan.html

[8] http://www.fansbuku.co.cc/2012/01/mengetahui-jenisjenis-e-commerce.html 
